\title{
The Degrading Value-based Orientations of the Linguistic Personality in the Infomedia of the Contemporary Internet Public Communication
}

\author{
E. V. Shirina \\ Dr. Sc. (Philosophy) \\ South Federal University \\ Rostov-on-Don,Russia \\ oc41@,bk.ru
}

\author{
G. I. Myasischev \\ Don State Technical University \\ Rostov-on-Don,Russia \\ georgy-2583@yandex.ru
}

\begin{abstract}
The article deals with the problem of degradation of the linguistic personality's value orientation in the modern information space. In this paper we determine the main directions of pragmatic study. We give the overview for the principles of the amateurism and pseudoscientific knowledge development. The article demonstrate formation of the main destructive directions for the linguistic personality`s degradation. We give examples to false orientation of a linguistic personality in a communicative space. The article shows that the linguistic personality in open communication reflects objectively existing features possession of the information culture and can actively influence the development of the linguistic community of modern media space. We determine the possibilities of mass communication in the conditions of mobile communication. On the basis of content analysis, media work features are revealed in the context of globalization and personality destructuring.
\end{abstract}

Keywords - linguistic personality, means of communication, mass media, dilettantism, pseudoscience

\section{INTRODUCTION}

Contemporary education demands for a permanent request in perfecting knowledge, solving educational problems via self-education by searching and studying vital information. The specific essense of the Internet facilitates a short-time search of urgent and varied data; at that, the time needed to obtain it is much shorter than in using traditional library resources. On the other hand, the information derived from the Internet in its quality is able to vary from highly professional to extremely low-grade. Through the contemporary professional activity getting more and more intense, the growing total rhythm of social life increases the requirement in a fast access to information with relevant quality. Therefore, the modern man is bound to independently determine the quality and reliability of the information obtained, which is quite hard for those who only have basic knowledge (within secondary school limits) about the science they are studying. Still, the nature of current life is that in order to successfully solve professional problems you need to have an access to education - which is not for everybody - every time you urgently need to get specialized in a particular science. Often, the man requires some particular knowledge, an algorithm to solve a practical problem, highlyspecialized information, some limited skills and habits. To achieve this, the man should resort to self-education, world experience, and the sources of knowledge offered by the present-day Internet.

The aim of our particular research is to study how the linguistic personality improves itself in Internet-communion from thepoint of view correlation between professional and nonpro approaches towards the content of obtainable data.

\section{COMMUNICATIVE PROCESSES IN MULTIMEDIA AND NETWORK SPACE OF THE INTERNET}

In the field of linguistic sciences, within the framework of graphic, lexical, and textual characteristics of communicative processes via the multimedia and network computer facilities, there have already been detected the key directions of research and achieved some palpable results. A.G. Avramova [1], I.V. Azarova [2], A.A. Atabekova [3], M.B. Bergelson [4], L.T. Bobrova [5] are the researchers of the nature of functioning of the virtual communication field.

The works by G.Guseinov [6], G.Ch. Huseynov [7], O.I. Ermakova [8] have discussed both the nature of language functioning in the infomedia created by computer networks and the features of creating a computer jargon. The characteristics of the hypertext as a phenomenon and, especially, the features of how the linguistic persona manifests themselves in the hypertext are discussed in the works by O. V. Dedova [9], O.A. Levonenko [10], A. Myshenkova [11] and others.

Nowadays, linguists have analyzed the nature of perceiving oral and written verbalized information. The work "Thinking and Speech" by L.S. Vygotski [11] deals with the fundamental concepts for the nature of speech and text being generated, its perception, some problems of evaluating verbalized information and its acquisition from the point of view of its authenticity and quality. The researcher univocally concludes that verbalized information undoubtedly possesses a certain value to the speech-creating individual. This largely explains why the contemporary human is forced to create an information flows via speech or (which is more frequent now) 
text but never explains the cause of dilettantism or pseudoscientific doctrines. What makes authors generate unreliable information? A.A. Leontyev argues that the creation of fake information in the speech-cognition environment could be explained by the specific self-positioning and selfrepresentation of the human thus requiring publicity at psychological, social, and speech levels [12, pp. 37-44].

Moreover, the cognitive modeling of linguist processes is still a pending key issue because they feature the doubling of speech content, i.e. the same individual in similar situations generates truthful and corrupt information basing on similar basic factors. In the 1970s, it was thought that the generation of information in the social communicative space was caused by the demand in such information, which was a priori accepted as reliable at least by its author (see as e.g. "The Probabilistic Model of Speech" by V.V. Nalimov) [13].

The fake messages were explained by some political intentions or by the author's general incompetence. Here we accept A.A. Leontyev`s approach as more appropriate. Most of the Internet content is far from being commercial and thus never yields any monetary gains to the creators. Therefore, speaking about whatever financial reasons for creating publications to any subject would be hardly productive.

Evidently, a certain psychological urge exists in creating texts with the content that is in fact a certain type of reality, alternative to the actual objective one. We feel here that the psycholinguistic (linguistic) personality of the author is quite similar to the one of a sci-fi writer who, by writing fiction, creates an irrational world. In our opinion, the part of the author's ego is highly critical in the book they write [12]. If the sci-fi author bases their work on the awareness of creating a reality different from the objective one, the author of an internet publication claims that their works are the accounts of the objective reality. Studying the individual style (idiostyle) of similar authors makes us conclude on the multifactor nature of this phenomenon. According to V.P. Grigoryev, idiostyle is the author's reflection on the language as a combination of text-creating constants of the creative personality. [14, pp. 4551]

\section{EVALUATION METHODS AND SOURCES OF INFORMATION}

Let us consider an example of an Internet publication targeted at reference and enlightenment ends:

"Treating epithets as tropes is quite a frequent mistake one can come across in the reference sources of both literature portals and reviews written by beginners. It is possible that some authors would say that this purely professional issue has nothing to do with a creative process. However, lack of care of such "trifles" may expose an amateur who would rather choose their own self-esteem - not in the others' eyes, but in their own - than literature, poetry with their age-long features" [15].

It is quite evident that relating the epithet to tropes or treating it as a separate category creates one of purely professional literary problems that means accepting one of the opinions that exist in the scientific community. This problem has come to life quite recently, however, in the historical paradigm; the epithet was related to tropes even in the Ancient World. It is extremely hard to accept its emphatic reference to such self-loving authors like Cicero, Trediakovski, Soumarokov and alike only basing on the notion that nowadays there's a different approach to classifying tropes. The author of the article adds that "In all fairness, it should also be added that you may often face metaphorization of the epithet (golden spike), however it is primarily an accentuated figure of speech, never aiming at establishing a meaningful concept-creating image, like it were with tropes" [15]; it merely makes one think of the biased interpretation of the notion of "metaphoric epithet", the essence of the figures of speech and the mechanism of creating imagery in fiction.

The authors have analyzed about 85 sources, claimed as "professional", offering innovative knowledge in humanities. The results are presented in Diagram 1 (pic. 1).

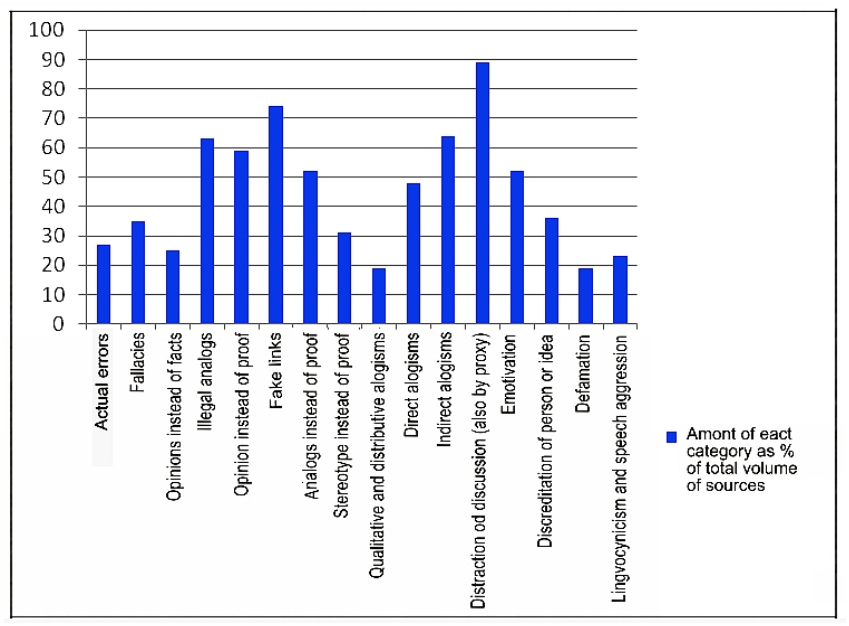

Pic. 1. Percentage of Errors and Manipulations Used Instead of Evidence in the Internet Professional Sources from the Total Number of the Sources Studied

We have placed a few most critical indices into a separate category, although lingvocynism is mostly used to discredit ideas or opponents; however, such manipulations quite rarely contrast with the most popular models of the cultural social speech behavior. Among the numerous examples of such errors we can list a few quite incredible statements of those who claim to be top professionals. As an example, in a specialized site that offers information support to postgraduate students, a "prominent scientist", probably basing on his own experience, refers to his colleagues at least as "scum" and university newsgroups as "shitcollectors"[16]. Quite a popular phenomenon in the contemporary mass media is the presence of numerous weird, in terms of common sense; "scientific" ideas of a possible attack of the URRS on Germany in 1938 (mind the absence of the common frontier!) [17], N.V. Gogol's plagiarism of the novel "Dead Souls" from A.S. Pushkin [18], the "world conspiracy" of historians who have cooked the myth of the Mongol -Tartar intervention [19], and heaps of other clumsy and manipulative articles willingly 
published by the same sources alongside with their academic and truly scientific publications (e.g. [22]).

Presently, no Internet user, from the valuecommunication angle of, is capable of determining a pseudoscientific product or the one by a dilettante without being properly educated.

\section{ASSESSMENT OF THE QUALITY OF INFORMATION BY A LINGUISTIC PERSONALITY}

By analyzing the linguistic persona of the author of a fake publication it is possible to shape up their speech portrait that will feature the following trends:

1. Most of such works are of an expressly educating nature. Irrespective of a formally declared category, they communicate some new, information, unknown to the user, or disclose a certain fake fact. It is also important that this "new" or "true" data is far from being new or true. At the lexicosemantic level, such publications feature an emphatic use of such lexical units and collocations as "the fact of the matter", "whereas", "as a matter of fact", "frankly speaking", expressions like "it is assumed that.... but", "contrary to the widespread fallacy...", "from the Soviet/liberal/religious point of view... but in fact" etc. Such markers on their own may not clearly indicate fake information, however their emphatic use along with straightforward assertions often point at fake statements.

2. Structurally, the text consists of one or a few assertions, not backed with any experimentally-based or mathematically-modeled objective data. Moreover, the system of facts may be mentioned but never presented, e.g. "the research shows that" (place, what research, the source - are never mentioned), "We/researchers/Western experts/ have studied and found..." (no other data available), "According to international practices..." (no indication of why the data is referred to the international experience, who it was obtained by and by means of what research).

3. The argumentation along such assertions is based on the logical substitution of facts by trying to influence the reader psychologically. Most often, the reasoning here is based on pseudoevident line of argument, inherently not supported by facts. The following is a spectacular example of such publication devoted to the work of M.M. Kheraskov:

"The nation that has become one of the European political leaders is also aiming at equaling in terms of culture. Trediakovski, Soumarokov, and Lomonosov developed a theory of writing verses in the Russian language, they successfully overhauled foreign poetic genres; however, the powerful nation has never had one thing - an epos of their own. Let me remind you, The chant about the Igor's Regiment was only discovered in 1792. Honestly, it's such a shame that the Greeks have The Iliad, the Italians have The Divine Comedy, the British have The Beowulf, The Germans have The Song of the Nibelungs, the French have The Song of Roland, even some Portuguese have The Lusiadas, so are we the worst? Whoever tried their hand at solving this problem, they all failed: Trediakovski had no success, Lomonosov quit in the midway, and now Kheraskov has picked up the torch." [20]

This author strongly insists on the new date of discovering The chant about the Igor's Regiment, even though the scientific community has long accepted the following time spectrum: 1792 - supposedly first mention, 1795 - actual preparation of the first "Catherine's" list, 1800 - first open publication. The author also substitutes the events (much later 1837 publication of the Song of Roland precedes the one of The Lay); he also substitutes the entity of the poem (using as the examples of the national epos and medieval poems), makes a factual mistake (The Lusiada instead of The Lusiadas), diminishes the whole nation by "even some Portuguese have The Lusiada". This very example points at the fact that the misconception about "Russia never having their own epos" is the result achieved by falsifying arguments and vigorous attempting on impacting the reader's emotions and ambitions.

4. The author declares himself as an expert in possession of special knowledge in order to attract a certain amount of trust that normally increases when such knowledge is shared by a professional, and this trick is often used by dilettantes. Here the global network user is forced to take for granted the author's claims of being a professional that may never be checked. It fact, the author has never been experienced in this particular field of knowledge. Being false and not true, the information starts shaping up as an absolute and trustworthy system of facts. To spot the truth here, the user has to have some relevant skills of an IT expert, capable of evaluating if not the information offered then at least the source.

5. Psychological Impact on the Reader. The key factor that helps convinces the reader in the authenticity of presented facts is the impact on their ego, emotions, personal preferences, and fears. Let us use the above quote again: "an amateur who would rather favor their own self-esteem" [15]. It is natural that the reader would choose to accept the author's thesis because for them "literature, poetry with their age-long features" are of key importance. Aggressive behavior, downgraded vocabulary, direct defamation and dehumanization of the opponent are some widely spread features of such quasi-professional publications [22, 23]. Their authors never accept other points of view; they actively oppose to "academism and retrogradism" (in fact, to objective facts) demanding "personal freedom".

\section{CONCLUSION}

Consequently, the concept of knowledge gets eroded by the society resulting in indifference and distrust to information sources. Potentially, any source of information may equally deliver fake and true-to-life information $[24,25]$. On the other hand, the degrading authenticity of information presupposes a frivolous attitude to the public presentation of any information in question. Multiple discrepancies are caused by lack of both the inner demand in the truthfulness of information and the responsibility for its being correctly presented. The widely described by mass media mistakes in the names of K.E. Tsiolkovski and A. Einstein on the bas-relief in the town of 
Bryansk [26], the drawing of the Schmeisser assault gun on the monument of M.T. Kalashnikov [27] and many others could be explained in many different ways, however the authors often demonstrate indifference to the mistakes they have made. Dilettantism is not accepted as a negative trait anymore. Instead, it is treated by the society as some everyday evocative environment that might be determined by the imperative "Relax!". The contemporary linguistic personality may not rely on their intuitive and cognitive skills to judge about the level of authenticity of information and does not insist on its obligatory verification. Instead, the society keeps continuous production of quasicompetent information to satisfy the authors' ambitions who claim that any idea that strikes their imagination is trustworthy and must be verbalized by all means.

\section{REFERENCES}

[1] A.G. Avramova. An electronic resource in the mirror of the opposition "spoken - written". Vestn. Moscow State University. Ser. 19, Linguistics and Intercultural Communication . 2004. vol. 3. pp. 119-129.

[2] I. V. Azarova 1996 Network representation of linguistic data (St. Petersburg). p. 310

[3] A.A. Atabekova Verbal communication on the site space in a comparative aspect . Materials of the Second International Conference "Communication: Conceptual and Applied Aspects" Under the general ed. I. N. Rozina .( Rostov -on-Don). 2004.p. 290

[4] $\mathrm{M} / \mathrm{B}$. Bergelson Language aspects of virtual communication . Bulletin of the Moscow State University. Ser. 19, Linguistics and Intercultural Communication . 2002.vol. 1.pp. 55-67.

[5] L.G. Bobrova 2001 Pragmatics of the network information text (on the material of the English language) Abstract. dis ... cand. philol. sciences. (M.). p. 25

[6] G. Ch. Guseinov Other languages. Notes on the anthropology of the Russian Internet: features of the language and literature of network people Access mode: www.nlo.magazine.ru/dog/tual/main8.html.According to. from the screen.

[7] Ermakova OI Features of computer jargon as a specific subsystem of the Russian language [Electronic resource] / O.I. Ermakov.- Access mode: $/ /$ www.dialog-21.ru/archive_article.asp?param $=6683 \&$ vol $=6077 .-$ In the entry. from the screen.

[8] O. V. Dedova Changing relations "author-reader" in the program of electronic hypertext . Bulletin of the Moscow State University. Ser. 9, Philology . 2005.vol. 6.pp. 30-45.
[9] O.A. Levonenko Linguistic personality in electronic hypertext Abstract. dis ... cand. philol. Sciences (Taganrog) 2004. p. 28

[10] A. Myshenkova Gender and age aspects of Internet use Access mode: www.flogiston.ru/projects/articles/strategy.shtml. In the entry. from the screen.

[11] L.S. Vygotsky 2000 Thinking and Speech. p.260

[12] A. A. Leontiev 1997 Fundamentals of psycholinguistics (M.: Sense) p. 287

[13] V.V. Nalimov 1987 Probabilistic model of language.p.310

[14] V.V. Grigoryev 1983 Grammar of idiostyle (Moskow). p.190

[15] On the paths and epithet. Conversation Seven Access mode: https://www.litprichal.ru/work/102824. In the entry. from the screen

[16] Stimulus for working on the dissertation Access mode: $\mathrm{http}: / / \mathrm{phdru} . \mathrm{com} /$ dissertation/stimul. In the entry. from the screen

[17] Strike of the USSR in fascist Germany ... in 1938 Access mode: https://topwar.ru/140491-udar-sssr-po-fashistskoy-germanii-v-1938godu.html. In the entry. from the screen

[18] E. Chernykh Gogol grew up from the maps of Pushkin. Access mode: https://www.rostov.kp.ru/daily/26649/3668920. In the entry. from the screen

[19] Why did they create a fake about the "Mongolian" invasion of Russia? Access mode: https://topwar.com/132429-zachem-sozdali-falshifku-promongolskoe-nashestvie.html. In the entry. from the screen

[20] Creativity M.M. Kheraskov Access mode: http://archive.critic-allzone.ru/poyezija/ 114/ heraskov .html. In the entry. from the screen

[21] K A Abulkhanova 1997 Russian mentality: cross-cultural and typological approaches // Russian mentality: issues of psychological theory and practice (Moscow: Institute of psychology RAS) p 37

[22] I. S. Jacobs and C. P. Bean, "Fine particles, thin films and exchange anisotropy," in Magnetism, vol. III, G. T. Rado and H. Suhl, Eds. New York: Academic, 1963, pp. 271-350.

[23] Y. Yorozu, M. Hirano, K. Oka, and Y. Tagawa, "Electron spectroscopy studies on magneto-optical media and plastic substrate interface," IEEE Transl. J. Magn. Japan, vol. 2, pp. 740-741, August 1987 [Digests 9th Annual Conf. Magnetics Japan, p. 301, 1982].

[24] O V Kliuchnikova and Pobegaylov O A 2016 Procedia Engineering 150 pp $2168-2172$

[25] O A Pobegaylov, G I Myasishchev and O E Gaybarian 2016 Procedia Engineering 150 pp 2173-2177

[26] In Bryansk renamed Tsiolkovsky and Einstein Access mode: https://www.rostov.kp.ru/daily/24586.5/756496. In the entry. from the screen

[27] The commission did not notice on the Kalashnikov monument the drawing of the German automaton Access mode: https://vz.ru/society/2017/9/22/885809.html. In the entry. from the screen 